\title{
Design of a Western Engineering “Green” Building
}

\author{
D. M. O’Carroll, E. K. Yanful, F. Berruti, R. O. Buchal \\ Faculty of Engineering \\ The University of Western Ontario \\ London, Ontario, CANADA
}

\begin{abstract}
The Faculty of Engineering proposes to replace an existing building at the University of Western Ontario with a modern, state of-the-art, environmentally friendly, and energy-efficient building designed by students. This is an ideal opportunity to expose students to an interdisciplinary design project involving every engineering discipline. Students were commissioned to design a building that achieves the highest possible Leadership in Energy and Environmental Design accreditation. Initial design work was performed by students as part of their capstone design courses in 2004/2005. In 2005/2006, two competing multidisciplinary teams of students conducted detailed integrated design work in collaboration with industry - including architects and engineering consulting firms - to tackle the structural, environmental, materials, mechanical and electrical requirements. The experience was very positive, but the degree of interdisciplinary collaboration was less than expected due to the departmental nature of existing capstone design courses.
\end{abstract}

\section{Introduction}

The Faculty of Engineering at the University of Western Ontario is in the midst of considerable expansion. There are currently 1560 full-time undergraduate students and 380 graduate students with significant growth in enrolment. In addition the number of faculty members has also grown exponentially in recent years. As a result existing classroom, laboratory and office space is nearing capacity. The Faculty of Engineering has, therefore, starting planning for the demolition of the existing BioEngineering Building and the construction of a new "Green" building to meet future space requirements.

The 30 year old Bio-Engineering Building, located adjacent to the Spencer Engineering building (Figure 1 ), was originally built to house a temporary (3 year) wind tunnel while the permanent Boundary Layer Wind Tunnel building was constructed. Upon completion of the permanent Boundary Layer Wind Tunnel the temporary structure was not demolished, as originally planned, but was converted to laboratory and office space for biochemical research.

Due to the planned temporary nature of this one-storey building, the Bio-Engineering Building was not built to the same standard as permanent structures at Western. It is an energy inefficient building with inadequate insulation; poor climate control, and a leaky unattractive roof. The building has needed frequent repairs over the years, proving to be expensive to operate and maintain. Given its close proximity to existing Faculty of Engineering buildings and the problems associated with the existing Bio-Engineering Building this site is the ideal location for a new, environmentally-friendly, state-of-the-art Green Building.

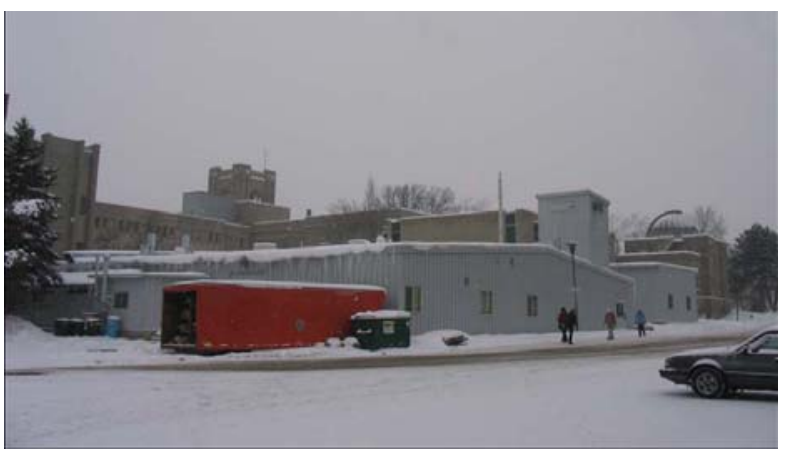

Figure 1. Existing Bio-Engineering Building and proposed site for the Green Building 


\section{Proposed Green Building}

The new building will be used as a Western Engineering Students Centre with facilities to meet the needs of present and future students. The Students Centre will serve as the focal point for students' life at Western Engineering. It will provide a special place where Engineering students can learn, study, and interact with one another on both academic and social levels, in an environmentally and ecologically minded atmosphere. The building will be a sustainable development education initiative that is unique in Canada, utilizing groundbreaking conservation concepts and practices, and future technologies. It will integrate technological and environmental aspects of Engineering to serve a vision and a purpose; it is not just another green building!

The proposed Green Building will be comprised of four floors with no basement, $1048 \mathrm{~m}^{2}$ per floor (11275 $\mathrm{ft}^{2}$ per floor). It will be located adjacent to Western's main Spencer Engineering Building and the new Thompson Engineering Building. It will be connected to both of these buildings via a $2^{\text {nd }}$ floor passageway, therefore greatly enhancing ease of movement between key areas of Western Engineering. It will provide for wheelchair and elevator access and a public building efficiency viewing station. Features of the Building will also include the following:

- First Floor: student club and team space as well as a cafeteria and social space that opens to an atrium (greenhouse/biosphere).

- Second Floor: graduate student office space.

- Third Floor: laboratory and office space to replace existing Bio-Engineering Building space.

- Fourth Floor: Library: Green energy and technologies laboratory. Laboratories will include a novel materials and green polymers laboratory, a green energy laboratory, air and water pollution treatment laboratory as well as a fuel cell and bio fuel laboratory.

A conceptual rendering of a possible Green Building was prepared by a local Architectural firm, as shown in Figure 2.

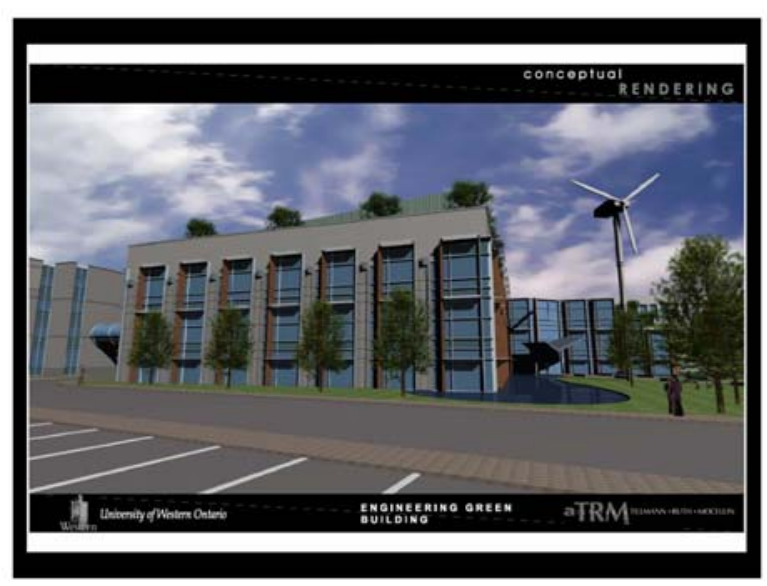

Figure 2. Conceptual rendering of proposed engineering green building

\section{The Green Building as an Interdisciplinary Project}

It is generally agreed that engineering students need to develop skills in working on interdisciplinary teams. Individual engineering departments address this by establishing team design projects, and students within those departments often incorporate knowledge from other disciplines in their designs. Departments also try to expose students in their programs to other disciplines.

However, it is rare for students to work on projects involving more than two disciplines. It is also rare for students to work on a design team with students from other disciplines.

The need for a new engineering building became apparent in the fall of 2003. At that time the Dean of Engineering and the Chairs of the various departments suggested that the design of this building would be an ideal project for the $4^{\text {th }}$ year capstone design courses.

The Engineering Green Building provides an ideal opportunity for students to work on an interdisciplinary project involving every discipline, including: civil engineering, chemical engineering, electrical engineering, integrated engineering, mechanical engineering, and software engineering.

\section{Student Capstone Design Criteria}

As part of their $4^{\text {th }}$ year capstone design course interdisciplinary teams of engineering students were 
commissioned to develop a sound design alternative for replacing the aging Biochemical Engineering Building with a modern, state-of-the-art, environmentally friendly, and energy-efficient building. The students would be assisted by Engineering faculty and external advisors (engineers, architects, landscape experts, green construction experts, etc.).

Students were asked to consider the following issues in their designs:

- Demolition of existing building and possible recycling of materials.

- Use of green materials, type of construction and type of insulation.

- Structural, foundation, structural frame, building envelope.

- Operational issues

- Minimum energy consumption, increased energy efficiency and use of renewable energy sources.

- Minimum (zero, if possible) storm water runoff.

- Minimum ecological footprint, use of renewable energy sources, eco-efficiency.

- Waste management and waste reduction.

- Indoor air quality.

- Esthetics, social impact, ecological significance to community.

- Educational value of the building.

The students were also asked to design their building in order to achieve the highest possible Leadership in Energy and Environmental Design (LEED) building accreditation (certified, silver, gold and platinum). The LEED accreditation system has been created by the U.S. Green Building Council [1] to encourage building designs that limit environmental impacts and give the building user a healthy and high-quality occupancy experience. The LEED accreditation guidelines are considered the standard for sustainable building design and construction. LEED criteria include the development of a sustainable site, water efficiency, consideration of energy consumption and atmospheric pollution, materials and resources used and indoor environmental quality.

\section{2004-2005 Design Class Design Experience}

In the first year of this new design project, students self selected and formed groups with other students in their own discipline (Chemical and Biochemical Engineering, Civil and Environmental Engineering, Electrical and Computer Engineering, Mechanical and Materials Engineering, Software Engineering or Integrated Engineering). The students then met with their faculty advisor to determine a project applicable to their discipline and to the new "Green Building". The student groups submitted a formal project proposal to their department capstone design course instructor early in the fall semester. The groups were responsible to meet various project milestones in the fall and early winter semester. While working on the projects, the students met with their faculty and external advisors on a regular basis to quickly resolve any questions the students had and to ensure that the design can be used for the construction of the new building. The student groups also meet with various campus departments (e.g. physical plant) to assess existing infrastructure and building guidelines and standards. The groups also polled individual students and student organizations to develop a building design that meets all of the occupants' needs. In March 2004, all groups presented their design in front of a panel of judges comprised of external judges and faculty members. Awards were given to the group with the most environmentally friendly design, the most innovative design and the best design. Students expressed high levels of satisfaction with the "Green" Building capstone design project. Part of their satisfaction resulted from working with fellow students (and friends) in their discipline. This group structure, however, limited the interdisciplinary nature of the designs with groups working on one specific aspect of the building. As a result, only discipline-specific subsystems were designed, with little overall systems integration. There was little communication between teams, resulting in overlap, duplication, and gaps. The departmental design courses and corresponding projects are described below.

\section{CBE 497 - Chemical Process and Plant Design}

CBE 497 is a highly structured plant design course with specific expectations. Students are required to design a process plant, following a standard methodology. As a result, the projects tend to be complex, stand-alone process plants with little 
integration with other systems. The two CBE 497 projects were:

- Waste Water Treatment and Recycling

- Harvesting of Rain and Snow Water (with MME 399 team)

It was expected that $\mathrm{CBE}$ and Integrated Engineering students would collaborate on the second project. In practice, there was little collaboration between the two teams.

\section{CEE 441 - Civil Engineering Design Project}

Civil engineering projects tend to take a systems approach, and include architectural design. Two teams developed overall building concepts, including architectural renderings. The CEE students attempted to collaborate with other teams, with mixed success. One of the designs is shown in Figure 3.

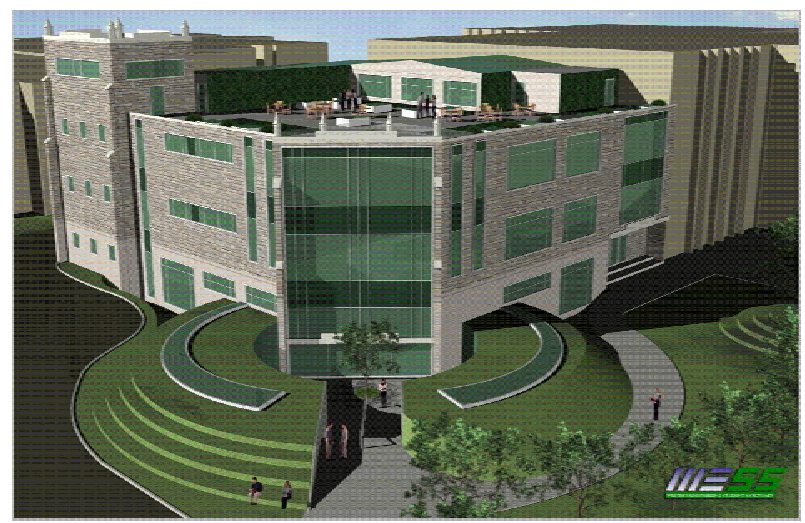

Figure 3. Conceptual rendering of 2005 Green Building design

\section{ECE 416 - Electrical/Computer Engineering Project}

ECE design projects focus more on prototype building and testing rather than conceptual and systems design. As a result, ECE students often design solutions from scratch rather than evaluating and incorporating existing technologies. The ECE teams tended to work independently from the other teams, even though there was obvious overlap with other projects. Their projects were:

\section{- Solar and Wind Power}

- Implementation of Heating, Ventilation and Air Condition (HVAC) Automation
- Assessment Electronic Sensory Devices

MME 399 - Integrated Engineering Design II

A team of third year Integrated Engineering students worked on harvesting rain and snow water. This was planned to be a collaborative project with CBE students, but in practice the projects were done independently.

\section{MME 419 - Mechanical Engineering Project}

A large number of Mechanical Engineering students elected to work on Green Building projects. Many of these projects were interdisciplinary, and collaboration with students from other departments was planned. In practice, the projects were done with little or no collaboration with other departments.

- Designs to Optimize Lighting Efficiency

- Design of HVAC System

- Designs for Active Solar Energy Collection

- Washroom Design

\section{SE 450 - Software Engineering Design}

Second and third-year software engineering students were assigned to assist other teams to develop control software for HVAC and lighting systems. In practice, the SE students worked independently.

\section{2005-2006 Design Class Design Experience}

In the second year of the "Green" Building design project the groups were modified to enhance interdisciplinary interactions between the students in each discipline and ensure cohesive building designs. Two interdisciplinary teams were established, composed of students from all disciplines. Overall the number of students in the "Green" Building capstone design project dropped from the previous year since students could not work with a large number of colleagues in their own discipline. The groups were approximately twice as large as groups in the previous year $(10-12$ persons/group) which, at times, made group management difficult. Each group was selfmanaged, and selected a group leader. However, the leader had no authority to force students to work together, attend meetings or provide updates on their individual component design. The students were still registered in different departmental capstone courses, and some students focused more on satisfying their own course requirements than on collaborating with 
students from other disciplines. One of the two teams established good collaboration between students; the other team splintered into several largely independent subprojects. Students had a similar deliverable schedule as the previous year and each group presented their project in front of a panel of external judges and faculty members in March. One group was given an award for the most environmentally friendly and technically innovative design. Conceptual renderings of the two designs are shown in Figure 42 and Figure 5. Similar to the previous year, the students reported high levels of satisfaction with the "Green" Building project in part because they worked on a project that will be constructed.

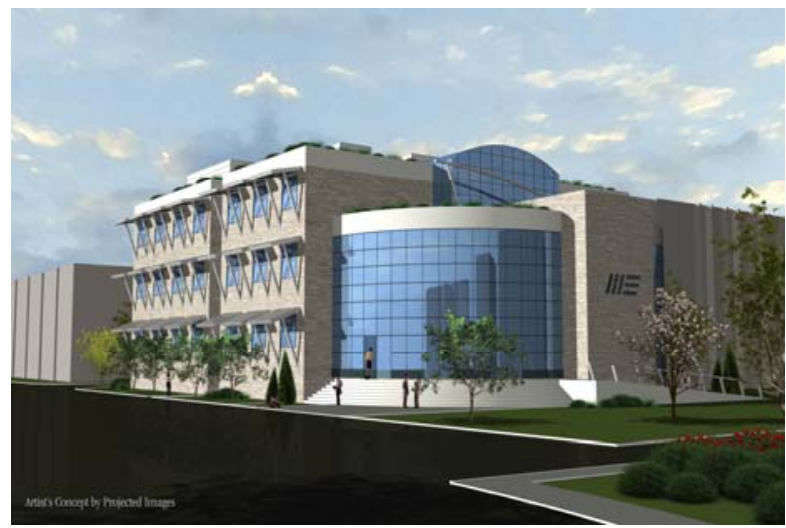

\section{Figure 4. Conceptual rendering of 2006 winning design of Green Building}

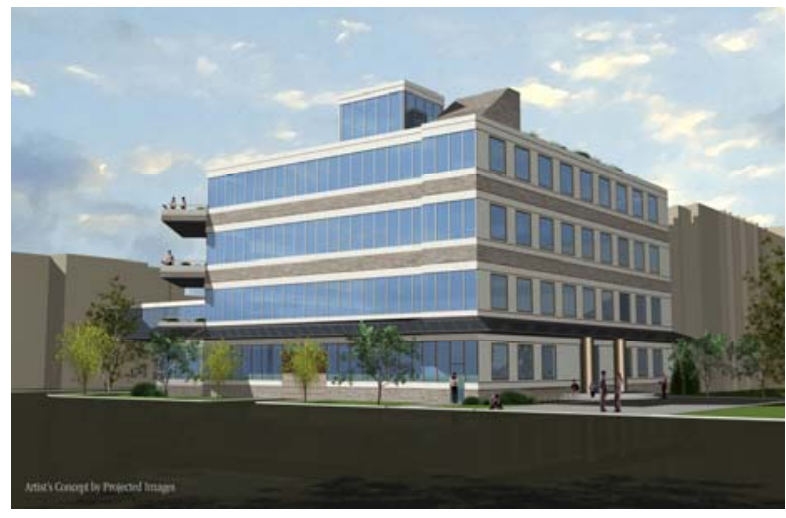

Figure 5. Conceptual rendering of 2006 runner-up design of Green Building

\section{Conclusions}

The Faculty of Engineering at the University of Western Ontario has identified the need for a new building to meet its current and future expansion needs.
The Faculty has proposed to build a new "Green" Building to meet these needs. The four engineering departments have decided to take advantage of this opportunity to incorporate the design of the "Green" Building in their capstone design courses. This new building will be "designed by students for students". Beginning in 2004 students, have completed preliminarily designs for this new building in accordance with LEED accreditation guidelines. Students gained a better understanding of the complexities and tremendous opportunities associated with the design of Green Buildings. The opportunity to work on a tangible project was a significant motivating factor for the students. This project also provided the students with valuable experience working in an interdisciplinary team environment typical of the work place they will enter upon graduation.

The existing departmental capstone design courses proved to be a barrier to interdisciplinary collaboration. Each course is independently administered, and has different deliverables and expectations. Our expectations that students would collaborate closely with students from other disciplines proved to be optimistic. A possible solution is to establish a common, interdisciplinary capstone design course.

\section{References}

[1] LEED: Leadership in Energy and Environmental Design, U.S. Green Building Council, http://www.usgbc.org/, accessed June 16, 2006. 